Article

\title{
Behaviour of Tetrabenazine in Acid Medium: Reassessment and Impact on Formulation
}

\author{
Laurent Ettouati ${ }^{1, *}$, Zoé Senta-Loys ${ }^{2}$, Sandrine Bourgeois ${ }^{2,3}$, Bernard Fenet ${ }^{4}$, \\ Marc Le Borgne ${ }^{1}\left(\mathbb{D}\right.$ and Hatem Fessi ${ }^{2}$
}

1 EA 4446 Bioactive Molecules and Medicinal Chemistry, SFR Santé Lyon-Est CNRS UMS3453-INSERM US7, Faculté de Pharmacie-ISPB, Université Claude Bernard Lyon, Université de Lyon, 18 avenue Rockefeller, F-69373, Lyon Cedex 8, France; marc.le-borgne@univ-lyon1.fr

2 LAGEP UMR 5007, CNRS, Université Claude Bernard Lyon 1, Université de Lyon, 43 bd du 11 novembre, F-69622 Villeurbanne, France; zoe.senta@gmail.com (Z.S.-L.); sandrine.bourgeois@univ-lyon1.fr (S.B.); hatem.fessi@univ-lyon1.fr (H.F.)

3 ISPB-Faculté de Pharmacie, Université Claude Bernard-Lyon 1, Université de Lyon, 8 avenue Rockefeller, F-69373, Lyon Cedex 8, France

4 Centre Commun de RMN, Université Lyon 1, Université de Lyon, 43 boulevard du 11 Novembre, F-69622 Villeurbanne Cedex, France; bernard.fenet@gmail.com

* Correspondence: laurent.ettouati@univ-lyon1.fr; Tel.: +33-4-78-77-70-82

Received: 14 December 2018; Accepted: 17 January 2019; Published: 20 January 2019

\begin{abstract}
Thorough studies of previous analytical stress data of tetrabenazine, a dopamine depleting agent, showed a potential susceptibility to acidic conditions. Hence, the behavior of tetrabenazine acidic solutions was studied by LC-MS and NMR spectroscopy. Reverse-phase LC-MS analysis of tetrabenazine acidic aqueous solutions consistently showed a main lipophilic impurity in a proportion of 15 to $20 \%$. NMR spectroscopy studies did not allow to completely ascertain its structure. However, we hypothesize an interconversion of trans-tetrabenazine with its unstable cis isomer via an open isoquinolinium intermediate. Evaluation of tetrabenazine integrity in orodispersible films was reassessed in light of these observations after formulation and during stability study. Even if interconversion of trans-tetrabenazine with its cis isomer was observed in orodispersible films containing tetrabenazine, this phenomenon seems not to have any consequences for the overall tetrabenazine bioavailability.
\end{abstract}

Keywords: tetrabenazine; deuteration; deuterated tetrabenazine; synthesis; stability; degradation impurities; acid medium; LC-MS; orodispersible film

\section{Introduction}

Tetrabenazine (3-isobutyl-9,10-dimethoxy-1,3,4,6,7,11b-hexahydro-2H-pyrido[2,1-a]isoquinolin-2one, TBZ, Xenazine ${ }^{\circledR}$, Figure 1), a dopamine depleting agent, is clinically used to manage movement disorders like chorea associated with Huntington's disease as well as off-label symptomatic treatment of many other hyperkinetic movement disorder [1-3]. More recently, valbenazine (Ingrezza ${ }^{\circledR}$ ) [4-6], an isoleucine derivative of a tetrabenazine metabolite and deutetrabenazine (Austedo ${ }^{\circledR}$ ), have been approved for treatment of same pathologies $[7,8]$. Deuterated drugs present as deutetrabenazine, the first approved deuterated drug, and have improved stability and better pharmacokinetics than their hydrogenated counterparts [9-13]. 


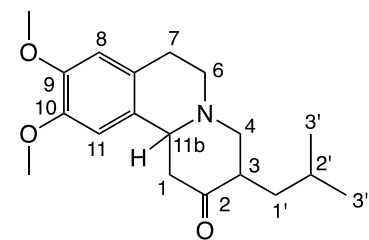<smiles>COc1cc2c(cc1OC)C1=CC(=O)C(CC(C)C)CN1CC2</smiles>

1,11b-dedihydrotetrabenazine

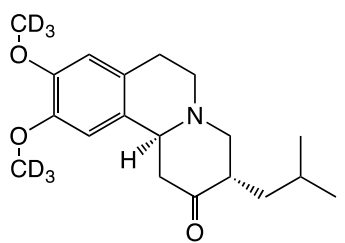

deutetrabenazine

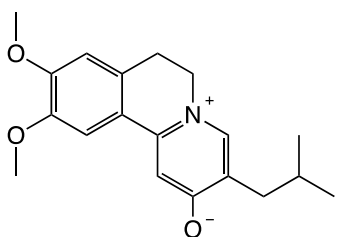

1,3,4,11b-detetrahydrotetrabenazine

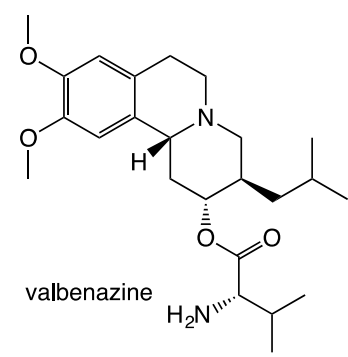

Figure 1. Structures of tetrabenazine (TBZ), deuterated TBZ, two tetrabenazine photolytic impurities and valbenazine.

Previous stability study of TBZ solution under Suntest ${ }^{\circledR}$ light exposure [14] has shown two major TBZ impurities identified as dedihydrotetrabenazine (DTBZ) and detetrahydrotetrabenazine (TTBZ), associated to strong discoloration (Figure 1). Close examination of reverse-phase LC-MS chromatograms revealed one additional weak peak at higher retention time in all TBZ samples exposed to acid stress conditions. Orodispersible films (ODF) of TBZ were previously developed for the paediatric administration $[15,16]$. This new form of drug administration called "ready to use" offers many advantages, such as no water needed for administration, enhanced pediatric population compliance ( $>6$ years), possibility of local action, dose accuracy compared to syrup, control of manufacturing processes, ease of handling and ease of portablity $[17,18]$. ODF were obtained by "casting/solvent evaporation" method [19] with TBZ pre-solubilization in acidic aqueous solution (citric acid). However, yellowing of TBZ ODF was observed during stability studies. This discoloration has been correlated with results obtained by Bourezg et al. [14], showing yellowing of TBZ in aqueous solution after strong light exposure. Thus, evaluation of TBZ integrity in ODF was investigated directly after formulation and during a stability study $\left(6\right.$ months, $\left.40{ }^{\circ} \mathrm{C}, 75 \% \mathrm{HR}\right)$ by LC-MS.

\section{Materials and Methods}

\subsection{Reagents and Solvents}

TBZ was provided by Safic Alcan (Puteaux, France). All reagents and solvents were of analytical grade. Water used for the LC-MS analysis was prepared by using Purelab Option Q water purification system from ELGA LabWater (Antony, France).

\subsection{Forced Acid Degradation Studies}

Stock solution of TBZ was prepared either in acetonitrile or citric acid aqueous solution $\left(20 \mathrm{mg} \cdot \mathrm{mL}^{-1}\right)$ and diluted with equivalent volumes of various acid solutions to obtain mixture at TBZ concentration of $10 \mathrm{mg} \cdot \mathrm{mL}^{-1}$ (Table 1). Each solution was compared to appropriate control. All samples were prepared away from light to avoid potential photolytic degradation. Each forced degradation condition was tested in triplicate. 
Table 1. Acidic hydrolytic stress conditions applied for tetrabenazine (TBZ) and ratio (\%) of observed TBZ/Unknown in LC-MS.

\begin{tabular}{|c|c|c|c|c|c|c|c|}
\hline $\begin{array}{c}\text { Stress } \\
\text { Condition }\end{array}$ & Solvent & Time & $\begin{array}{c}\text { Temp. } \\
\left({ }^{\circ} \mathrm{C}\right)\end{array}$ & Visual Observation & $\begin{array}{c}t_{\mathrm{r}} \mathrm{TBZ} \\
(\mathrm{min})\end{array}$ & $\begin{array}{c}t_{\mathrm{r}} \\
\text { Unknown } \\
(\min )\end{array}$ & Ratio (\%) \\
\hline No & $\mathrm{ACN}$ & One week & 4 & limpid colorless & 1.847 & - & - \\
\hline No & $\mathrm{ACN}+\mathrm{H}_{2} \mathrm{O}$ & $70 \mathrm{~h}$ & 70 & light yellow & 1.853 & 2.336 & $79: 21$ \\
\hline Acid & $\mathrm{HCl} 0.1 \mathrm{M}$ & $70 \mathrm{~h}$ & 70 & dark yellow-orange & 1.837 & 2.314 & $77: 23$ \\
\hline Acid & $\mathrm{HCl} 1 \mathrm{M}$ & $16 \mathrm{~h}$ & 70 & dark orange & 1.977 & 2.562 & $84: 16$ \\
\hline Acid & $\mathrm{HCl} 1 \mathrm{M}$ & $70 \mathrm{~h}$ & 70 & dark brown & 1.850 & 2.332 & $78: 22$ \\
\hline Acid & Citric acid $1.5 \mathrm{M}$ & $70 \mathrm{~h}$ & 70 & light yellow & 1.852 & 2.334 & $79: 21$ \\
\hline
\end{tabular}

\subsection{Instrumentation and Chromatographic Separation Conditions}

\subsubsection{LC-MS Analyses}

Liquid chromatography (LC) analysis was carried out by ultra-performance liquid chromatography (UPLC) Agilent 1290 Infinity system coupled to an Agilent 6120 Quadrupole mass spectrometer equipped with an electrospray ionization source (positive ESI mode) (Agilent Technologies, Santa Clara, CA, USA). The chromatographic separation was performed on a reversed phase column Zorbax Eclipse + C18 Agilent $(50 \mathrm{~mm} \times 2.1 \mathrm{~mm} ; 1.8 \mu \mathrm{m})$. The LC method and mass spectrometry analysis parameters were the same as described previously [14].

\subsection{Syntheses and Structural Characterization of $\left[1,1-d i-{ }^{2} H, 3-{ }^{2} H\right]$-Tetrabenazine $\left(\left[1,1-d i-{ }^{2} H, 3-{ }^{2} H\right]-T B Z\right)$}

\subsubsection{Materials and Methods}

NMR spectra were recorded on a Bruker AV300 (300 MHz for ${ }^{1} \mathrm{H}$ and $75 \mathrm{MHz}$ for ${ }^{13} \mathrm{C}$ ), a Bruker AV400 (400 MHz for ${ }^{1} \mathrm{H}$ and $133 \mathrm{MHz}$ for ${ }^{13} \mathrm{C}$ ) and a Bruker AV500 (500 MHz for ${ }^{1} \mathrm{H}$ and $125 \mathrm{MHz}$ for ${ }^{13} \mathrm{C}$ and $2 \mathrm{D}$ experiments) using $\mathrm{D}_{2} \mathrm{O}$, DMSO- $d_{6}$ or $\mathrm{D}_{2} \mathrm{O}$ and DMSO- $d_{6}$ in mixture with acetic acid or citric acid as solvents. Off-resonance ROESY (Rotating frame nuclear Overhauser effect spectroscopy) experiments were carried out according to Bax and Davis [20] and Desvaux et al. [21]. Spectra were processed with NMR notebook 2.80 (NMRTEC, Ilkirch-Graffenstaden, France) and TopSpin 4.0.6 (Bruker BioSpin, Billerica, MA, USA). Chemical shifts $(\delta)$ are referred to that of the solvent.

\subsubsection{Synthesis of $\left[1,1-\mathrm{di}^{2}-\mathrm{H}, 3-{ }^{2} \mathrm{H}\right]$-Tetrabenazine}

A tetrabenazine sample $(0.150 \mathrm{~g}, 0.473 \mathrm{mmol})$ was dissolved in $1.5 \mathrm{M}$ citric acid $/ \mathrm{D}_{2} \mathrm{O}$ solution $(15 \mathrm{~mL})$, and the solution was refluxed for $16 \mathrm{~h}$ under inert atmosphere. The solution was then neutralized with sodium carbonate to $\mathrm{pH} 11$ and extracted with ethyl acetate $(3 \times 20 \mathrm{~mL})$. The combined organic phases were washed with brine, dried over sodium sulfate and concentrated under reduced pressure. The title product was obtained in quantitative yield. $\left[1,1-\mathrm{di}-{ }^{2} \mathrm{H}, 3-{ }^{2} \mathrm{H}\right]$-tetrabenazine. TLC (silica) $R_{\mathrm{f}} 0,43$ cyclohexane/ethyl acetate: 7:3 (UV+ $\left.254 \mathrm{~nm}\right)$. NMR ${ }^{1} \mathrm{H}\left(300 \mathrm{MHz}, \mathrm{DMSO}-d_{6}, \delta\right.$ ppm) 6.69 (2 H, s, $2 \mathrm{HPh}), 3.71$ (3 H, s, OCH $), 3.44$ (s, $1 \mathrm{H}, \mathrm{H}-11 \mathrm{~b}), 3.24$ (1 H, J = 11.2 Hz, H-4), 3.12 (1 H, m, H-6), 2.92 (1 H, m, H-7), 2.67 (1 H, m, H-7), 2.48 (1 H, m, H-6), 2.27 (1 H, d, J = 12.1 Hz, H-4), 1.80-1.62 (2 H, m, $\left.-\mathrm{CH}_{2}-\mathrm{CH}\left(\mathrm{CH}_{3}\right)_{2}\right), 1.29\left(1 \mathrm{H}, \mathrm{m}, \mathrm{CH}\left(\mathrm{CH}_{3}\right)_{2}\right), 0.98\left(3 \mathrm{H}, \mathrm{d}, J=6.1 \mathrm{~Hz}, \mathrm{CH}_{3}\right), 0.93(3$ $\left.\mathrm{H}, \mathrm{d}, J=6.1 \mathrm{~Hz}, \mathrm{CH}_{3}\right) .{ }^{13} \mathrm{C}$ NMR $\left(75 \mathrm{MHz}, \mathrm{CDCl}_{3}, \delta \mathrm{ppm}\right) 195.50$ (C-2), $156.64(\mathrm{C}-9), 151.49$ (C-10), 148.06 (C-11b), 128.98 (C-7a), 120.84 (C-11a), 110.41 (C-8 or C-11), 108.28 (C-11 or C-8), 94.27 (C-1), 56.12 $\left(\mathrm{CH}_{3} \mathrm{O}\right), 56.10\left(\mathrm{CH}_{3} \mathrm{O}\right), 55.83(\mathrm{C}-4), 49.12(\mathrm{C}-6), 42.03(\mathrm{C}-3), 37.53\left(\mathrm{C}-1^{\prime}\right), 28.52(\mathrm{C}-7), 25.57\left(\mathrm{C}-2^{\prime}\right), 23.60$ $\left(\mathrm{CH}_{3}\right), 21.89\left(\mathrm{CH}_{3}\right)$. 


\subsection{Characterization of TBZ Integrity in ODF}

\subsubsection{Extraction of TBZ}

The composition of each ODF analyzed are shown in Table 2. ODF were cut and weighted to obtain a mass of $10 \mathrm{mg}$. Each sample was introduced in a glass hemolysis tube containing $2 \mathrm{~mL}$ of $\mathrm{ACN}$ and mixed during $1 \mathrm{~min}$ with a vortex at $3000 \mathrm{rpm}$. Then, the solution was collected and diluted with ACN to obtain a TBZ concentration of $0.5 \mathrm{mg} \cdot \mathrm{mL}^{-1}$. After filtration through a $0.22 \mu \mathrm{m}$ Nylon membrane (Millipore ${ }^{\circledR}$ ), samples were analyzed by reverse-phase LC-MS in the same conditions used for forced acid degradation studies.

Table 2. Overview of orodispersible films (ODF) composition. HPMC: Hydroxypropylmethylcellulose; PVP: Povidone; PUL: Pullulan; HEC; Hydroxyethylcellulose.

\begin{tabular}{cccccc}
\hline Formulation & $\begin{array}{c}\text { Polymer } \\
\text { Matrix (\%) }\end{array}$ & TBZ (\%) & $\begin{array}{c}\text { Citric Acid } \\
\mathbf{( \% )}\end{array}$ & $\begin{array}{c}\text { Glycerol } \\
\mathbf{( \% )}\end{array}$ & $\begin{array}{c}\text { Sorbitol } \\
\text { (\%) }\end{array}$ \\
\hline HPMC-ODF (F1) & 50.00 & 15.00 & 15.00 & 12.00 & 8.00 \\
PVP-ODF (F2) & 54.35 & 16.30 & 16.30 & 13.05 & - \\
PUL-ODF (F3) & 54.35 & 16.30 & 16.30 & 13.05 & - \\
HEC-ODF (F4) & 56.80 & 17.05 & 17.05 & - & 9.10 \\
\hline
\end{tabular}

\subsubsection{Condition of Stability Study}

ODF were stored in sealed aluminum strips and stability (ICH Q1-R2) was investigated at $40{ }^{\circ} \mathrm{C}$; $75 \%$ HR (accelerated storage conditions) for 6 months. Film samples of each formulation were withdrawn at 1,3, and 6 months for LC-MS analyses.

\section{Results}

\subsection{Acid-Forced Degradation Studies and LC-MS Analyses}

Tetrabenazine behavior in different acid media was implemented as shown in Table 1. These analyses confirm initial observations indicating apparition in all samples treated with acid of an additional signal in LC-MS corresponding to a more lipophilic compound ( $t_{\mathrm{r}}$ at 2.3 to $2.5 \mathrm{~min}$ ) in 15 to $20 \%$ proportion (see Table 1 and Figure S1 in Supplementary Materials). It is interesting to note its presence in chromatogram of TBZ sample dissolved in $\mathrm{ACN} / \mathrm{pH} 6.5$ deionized water mixture heated to $70{ }^{\circ} \mathrm{C}$ for $70 \mathrm{~h}$. On the other hand, TBZ is stable in solution in acetonitrile and kept away from light at $4{ }^{\circ} \mathrm{C}$ for at least one week. In isocratic condition used for chromatographic analysis, TBZ control elutes at $t_{\mathrm{r}} 1.85 \mathrm{~min}$ with a protonated molecular ion $[\mathrm{MH}]^{+}$at $\mathrm{m} / \mathrm{z} 318.2$ and the unknown more lipophilic compound with $t_{\mathrm{r}} 2.3$ to $2.5 \mathrm{~min}$ displays the same $\mathrm{m} / \mathrm{z}$ ratio than TBZ.

\subsection{NMR Studies of TBZ in Acid Medium}

TBZ instability in an acid medium has been confirmed in ${ }^{1} \mathrm{H}$ NMR by dissolving a TBZ sample in a mixture of deuterated acetic acid $/ \mathrm{D}_{2} \mathrm{O}$ or $1.5 \mathrm{M}$ citric acid $/ \mathrm{D}_{2} \mathrm{O}$ with continuous monitoring (see Figure S2 in Supplementary Materials). This instability was practically immediate and did not evolve significantly with time on a scale of a few hours. The ${ }^{1} \mathrm{H}$ NMR spectrum showed significant modifications in the chemical shifts of some TBZ protons, particularly $\mathrm{H}-11 \mathrm{~b}$ probably deshielded by nitrogen protonation with the appearance of signals between 1.5 and $2 \mathrm{ppm}$ and between 4.2 and $4.5 \mathrm{ppm}$ (see Figure S3A,C in Supplementary Materials). Furthermore, aromatic protons area showed apparition of signals accounting for at least two additional compounds (see Figure S3B in Supplementary Materials). In DMSO- $d_{6}, \mathrm{TBZ} \mathrm{H}-8$, and $\mathrm{H}-11$ aromatic protons appeared at around $6.70 \mathrm{ppm}$ as two close singlets while in $1.5 \mathrm{M}$ citric acid $/ \mathrm{D}_{2} \mathrm{O}$ solution three couples of singlets were observed at 6.56/6.41 ppm, 6.53/6.46 ppm and 6.51/6.40 ppm, respectively. Complementary 2D NMR spectra $\left({ }^{1} \mathrm{H}^{-1} \mathrm{H}\right.$ COSY, ${ }^{1} \mathrm{H}_{-}{ }^{13} \mathrm{C}$ HSQC, ${ }^{1} \mathrm{H}_{-}{ }^{13} \mathrm{C}$ HMBC experiments) did not identify with certainty the 
nature of these compounds that appeared in aqueous acidic environments. However, it has been noted an exchange phenomenon in ROESY spectrum for the $4.45 \mathrm{ppm}$ signal. It must be stressed that TBZ spectrum stayed identical for one night in $1.5 \mathrm{M}$ acetic acid/DMSO- $d_{6}$ or DMSO- $d_{6}$ alone. However, we noted puzzling simplification of TBZ spectra after $48 \mathrm{~h}$ in acetic acid/ $\mathrm{D}_{2} \mathrm{O}$ with loss of coupling for the $4.30 \mathrm{ppm}$ signal. We hypothesize some proton-deuterium exchange phenomena, which was confirmed by refluxing TBZ sample in $1.5 \mathrm{M}$ citric acid $/ \mathrm{D}_{2} \mathrm{O}$ for $16 \mathrm{~h}$. The ${ }^{1} \mathrm{H}$ NMR spectrum of the resulting instable compound, $\left[1,1-\mathrm{di}_{-}{ }^{2} \mathrm{H}, 3-{ }^{2} \mathrm{H}\right]-\mathrm{TBZ}$, shows the disappearance of protons $\mathrm{H}-1 \mathrm{a} / \mathrm{H}-1 \mathrm{~b}$ and H-3 with concomitant simplification of H-11b and H-4 (see Figure S4 in Supplementary Materials). Its formation is easily explained by enolization of the $\mathrm{C}=\mathrm{O}$ in 2-position and subsequent deuteration.

\subsection{LC-MS Analyses of TBZ Contained in ODF}

TBZ results obtained after ODF extraction are summarized in Table 3 (see Figure S6 in Supplementary Materials for complete set of data). At $T=0$, the appearance of a more lipophilic peak was observed in a proportion from 14.2 to $17.4 \%$ by LC-MS. After 3 months of stability, the percentage of the second more lipophilic component was decreased in sample F2 at $4.4 \%$. This decrease was also observed in F4 after 6 months of stability, while, the proportion was consistent during this time in samples F1 and F3.

Table 3. Overview of visual observations and \% of TBZ $\left(t_{\mathrm{r}} 2.9-3.3 \mathrm{~min}\right)$ and unknown compound ( $t_{\mathrm{r}}$ 3.7-4.5 $\mathrm{min}$ ) in LC-MS analyses at $T=0$ and after 3 and 6 months of stability. LC-MS separation conditions are the same as in Reference [14] (see Section 2.3.1).

\begin{tabular}{cccc}
\hline Sample & Visual Observation & TBZ (\%) & Unknown (\%) \\
\hline \multicolumn{4}{c}{ ODF at $T=0$, ambient temperature $(n=3)$} \\
F1 & Homogeneous, transparent, slightly yellow & $78.4 \pm 0.9$ & $17.4 \pm 0.3$ \\
F2 & Homogeneous, transparent, no colour & $83.2 \pm 2.3$ & $14.2 \pm 2.2$ \\
F3 & Homogeneous, transparent, no colour & $81.2 \pm 0.5$ & $17.2 \pm 0.3$ \\
F4 & Homogeneous, transparent, no colour & $82.3 \pm 0.9$ & $14.6 \pm 0.2$ \\
\hline \multicolumn{4}{c}{ ODF stored at 40 ${ }^{\circ}$ C, 75\% HR after 3 months $(n=3)$} \\
F1 & Homogeneous, transparent, yellow & $74.2 \pm 0.7$ & $17.2 \pm 0.4$ \\
F2 & Homogeneous, opaque area, slightly yellow & $91.2 \pm 0.6$ & $4.4 \pm 0.5$ \\
F3 & Homogenenous, transparent, slightly yellow & $79.7 \pm 0.3$ & $15.7 \pm 0.1$ \\
F4 & Heterogeneous, opaque area, slightly yellow & $81.0 \pm 0.3$ & $14.2 \pm 0.3$ \\
\hline & ODF stored at 40 ${ }^{\circ}$ C, 75\% HR after 6 months $(n=3)$ & \\
\hline F1 & Homogeneous, transparent, yellow & $80.1 \pm 0.1$ & $16.3 \pm 0.1$ \\
F2 & Homogeneous, opaque area, slightly yellow & $89.5 \pm 0.7$ & $6.5 \pm 0.6$ \\
F3 & Homogenenous, transparent, slightly yellow & $84.3 \pm 0.1$ & $14.1 \pm 0.6$ \\
F4 & Heterogeneous, opaque area, slightly yellow & $92.65 \pm 0.7$ & $6.0 \pm 0.7$ \\
\hline
\end{tabular}

\section{Discussion}

TBZ is marketed as the racemic trans form due to thermodynamic instability of the cis isomers. The stereogenic instability of the 2-oxobenzo[a]quinolizine nucleus substituted in position 3 in acidic medium is well documented [22,23]. Thus, we hypothesize the interconversion of trans-TBZ via the open isoquinolinium structure (Figure 2) with cis-TBZ. This involves racemization at both centers C-11b and C-3 by reversible Mannich reaction (C-11b) and by reversible enolization (C-3) [23]. An exchange phenomenon in ROESY spectrum between signals at 4.45 ppm and 4.65 ppm (see Figure S5A in Supplementary Materials) has been noted which is possibly assigned to intermediate species (see Figure S5B in Supplementary Materials). In the case of acid aqueous stress tests, the appearance of the less polar LC-MS compound might correspond to the cis racemic species formed in acid aqueous solution. ${ }^{1} \mathrm{H}$ NMR of TBZ in acidic aqueous condition would indicate the presence of the cis derivative and possibly open intermediate in continuous equilibrium. NMR kinetic studies have also been 
done over time to monitor trans-cis interconversion to a fixed $\mathrm{pH}$ and/or with temperature variation. A fixed $\mathrm{pH}$ kinetic study at room temperature showed a very fast interconversion after addition of acid and no longer evolved significantly over time (see Figure S7 in Supplementary Materials). Variable temperature kinetic study showed total disappearance of signals at 6.51/6.40 ppm and partial disappearance of signals at 6.56/6.41 ppm with general low field shifting (see Figure S8 in Supplementary Materials). Attempts to isolate in a solid state the hypothetical cis-TBZ isomer by extraction in organic phase after alkalinization were unsuccessful. Samples obtained from these extractions and checked in LC-MS showed intact trans-TBZ and did not show the presence of the more lipophilic impurity. The cis-TBZ isomer is probably unstable (kinetic product) and converts to the trans-TBZ isomer (thermodynamic product). In our hand, the cis-TBZ isomer is only observable in acid solution regardless of temperature. It is noteworthy that the actual drug for patients is unsalified (base form) and there is probably no cis-TBZ isomer in the actual drug for patients.

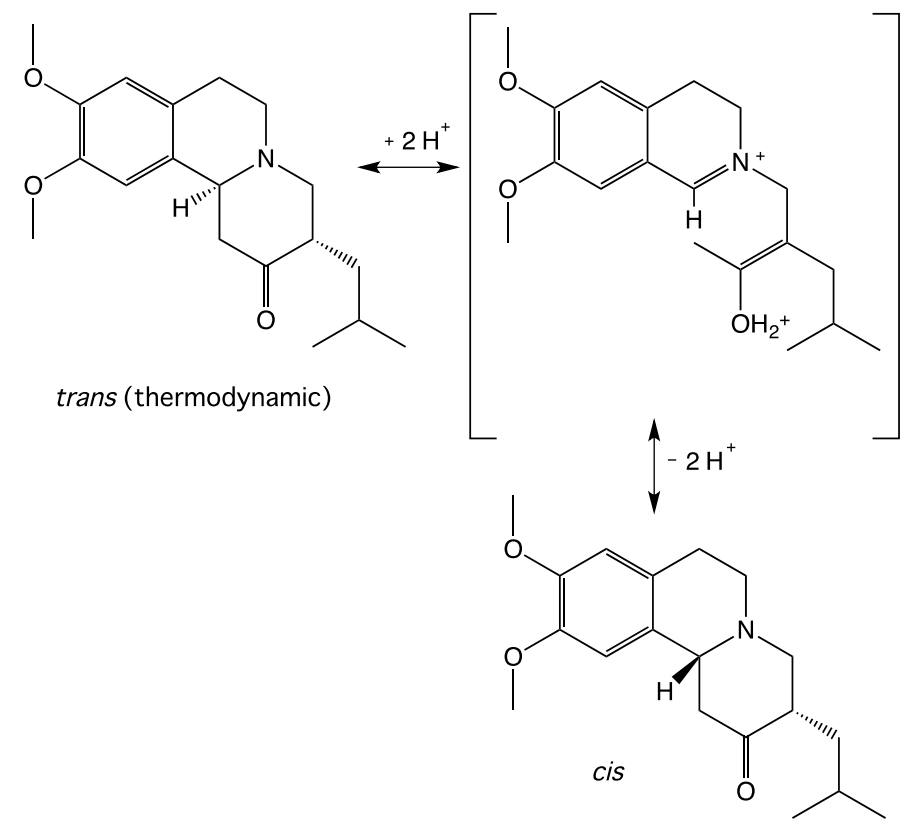

Figure 2. Hypothetical interconversion between trans-TBZ and cis-TBZ (only one enantiomer is depicted) in acidic medium.

TBZ was formulated as an orodispersible film for paediatric administration by the solvent casting/evaporation method $[15,16]$. Because TBZ was poorly soluble in aqueous solution excepted in acidic aqueous condition, the use of aqueous citric acid was required to dissolve and mix TBZ and polymer in solution. Indeed, organic solvent (e.g., ethanol) was not recommended for the paediatric population [24], and citric acid offered other advantages, such as palatability enhancement and plasticizer effect on the formulation [18]. However, as shown in this work, acid aqueous condition for TBZ-loaded ODF formulation generates partial trans-TBZ interconversion with cis-TBZ. The citric acid in ODF would allow partial interconversion in cis form, and this is more or less maintained over time depending on the matrix polymer used (presence or not of hydrogen bonds and good miscibility). We hypothesize that apparition of the opaque area after 3 months in F2 and 6 months in F4 (Table 3) is linked to the transformation of cis-TBZ into trans-TBZ which recrystallized. Previously, Senta-Loys et al. highlighted TBZ recrystallization from ODF composed of povidone (PVP) and hydroxyethylcellulose (HEC) (see samples F2 and F4, respectively, in this present study) [16]. This recrystallization was theoretically explained by the lack of hydrogen bonding with PVP and no vitrification effect of HEC. Indeed, TBZ has been characterized as amorphous solid dispersion and parameters, such as H-bond [25] and no "anti-plasticization" effect [26], play an important role to decrease molecular mobility and maintain system stability. Because of molecular dispersion of TBZ was suggested [15], 
LC-MS analyses were investigated. Thus, results obtained in this context showed changes occurred before recrystallization step. Indeed, we assumed the first step of the system reorganization was based on interconversion of cis-TBZ with trans-TBZ implying molecular mobility of the active pharmaceutical ingredient (API) in the polymer matrix. Extensive CPMAS (Solid-state Cross-Polarization Magic Angle Spinning) ${ }^{13} \mathrm{C}$ NMR measurements have also been done on tetrabenazine-loaded films with and without citric acid but did not give further information.

\section{Conclusions}

In the present study, standardization of TBZ behavior under acidic condition was investigated to explain preliminary observations showing an additional peak at higher retention time generated after aqueous acid exposure. Extensive experiments employing the use of NMR spectrometry and LC-MS analyses have led us to propose interconversion of trans-TBZ with cis-TBZ. However, as the solid-state cis-TBZ isomer isolation is impossible and under the hypothesis of interconversion between trans-TBZ and cis-TBZ, further investigations need to be conducted to confirm it, for example, DFT calculations [27].

Supplementary Materials: The following data are available online at http:/ / www.mdpi.com/1999-4923/11/1/ 44/s1. Figure S1: LC-MS analysis; Figure S2: TBZ $500 \mathrm{MHz}{ }^{1} \mathrm{H}$ NMR spectra; Figure S3: Expanded TBZ $500 \mathrm{MHz}$ ${ }^{1} \mathrm{H}$ NMR spectra; Figure S4: Deuterated TBZ $500 \mathrm{MHz}{ }^{1} \mathrm{H}$ NMR spectrum; Figure S5: ROESY experiments; Figure S6. LC-MS data for analyses of TBZ contained in ODF; Figure S7. Kinetic experiments on TBZ in $\mathrm{D}_{2} \mathrm{O} /$ acetic acid at $24{ }^{\circ} \mathrm{C}$; Figure S8. Kinetic experiments on TBZ in $\mathrm{D}_{2} \mathrm{O} /$ citric acid at variable temperatures.

Author Contributions: Conceptualization, L.E. and Z.S.-L.; Formal analysis, S.B.; Funding acquisition, M.L.B. and H.F.; Investigation, L.E., Z.S.-L. and B.F.; Methodology, S.B.; Supervision, S.B., M.L.B. and H.F.; Writing-original draft, L.E. and Z.S.-L.; Writing—review and editing, L.E., Z.S.-L. and M.L.B.

Funding: The present work was supported by the project Fonds Unique Interministériel (FUI) "Forms 4Kids".

Acknowledgments: The "Institut des Sciences Pharmaceutiques et Biologiques" (ISPB) of Lyon is gratefully acknowledged (special thanks to François Locher) for the funding of an UPLC-DAD-MS system, a powerful analytical tool, also useful for "connecting researchers". Bachir Abida is gratefully acknowledged for help in forced acid degradation studies. Ghania Hamdi-Degobert (ISPB, Lyon) is also gratefully acknowledged for unpublished results concerning HPLC analysis of TBZ samples subjected to acidic stress conditions.

Conflicts of Interest: The authors declare no conflict of interest.

\section{References}

1. Chen, J.J.; Ondo, W.G.; Dashtipour, K.; Swope, D.M. Tetrabenazine for the treatment of hyperkinetic movement disorders: A review of the literature. Clin. Ther. 2012, 34, 1487-1504. [CrossRef] [PubMed]

2. Müller, T. Investigational agents for the management of Huntington's disease. Expert Opin. Investig. Drugs 2017, 26, 175-185. [CrossRef] [PubMed]

3. Kaur, N.; Kumar, P.; Jamwal, S.; Deshmukh, R.; Gauttam, V. Tetrabenazine: Spotlight on drug review. Ann. Neurosci. 2016, 23, 176-185. [CrossRef] [PubMed]

4. Caroff, S.N.; Aggarwal, S.; Yonan, C. Treatment of tardive dyskinesia with tetrabenazine or valbenazine: A systematic review. J. Comp. Effect. Res. 2017, 7, 135-148. [CrossRef] [PubMed]

5. Müller, T. Valbenazine for the treatment of tardive dyskinesia. Expert Rev. Neurother. 2017, 17, 1135-1144. [CrossRef] [PubMed]

6. Sarva, H.; Henchcliffe, C. Valbenazine as the first and only approved treatment for adults with tardive dyskinesia. Expert Rev. Clin. Pharmacol. 2018, 11, 209-217. [CrossRef] [PubMed]

7. Paton, D.M. Deutetrabenazine: Treatment of hyperkinetic aspects of Huntington's disease, tardive dyskinesia and Tourette syndrome. Drugs Today 2017, 53, 89-102. [CrossRef]

8. Citrome, L. Deutetrabenazine for tardive dyskinesia: A systematic review of the efficacy and safety profile for this newly approved novel medication -What is the number needed to treat, number needed to harm and likelihood to be helped or harmed? Int. J. Clin. Pract. 2017, 71, e13030. [CrossRef]

9. Cummings, M.A.; Proctor, G.J.; Stahl, S.M. Deuterium tetrabenazine for tardive Ddyskinesia. Clin. Schizophr. Relat. Psychoses 2018, 11, 214-220. [CrossRef] 
10. Dean, M.; Sung, V.W. Review of deutetrabenazine: A novel treatment for chorea associated with Huntington's disease. Drug Des. Dev. Ther. 2018, 12, 313-319. [CrossRef]

11. Rodrigues, F.B.; Duarte, G.S.; Costa, J.; Ferreira, J.J.; Wild, E.J. Tetrabenazine versus deutetrabenazine for Huntington's disease: Twins or distant cousins? Mov. Disord. Clin. Pract. 2017, 4, 582-585. [CrossRef] [PubMed]

12. Howland, R.H. Deuterated drugs. J. Psychosoc. Nurs. Ment. Health Serv. 2015, 53, 13-16. [CrossRef] [PubMed]

13. Mullard, A. Deuterated drugs draw heavier backing. Nat. Rev. Drug Discov. 2016, 15, 219. [CrossRef] [PubMed]

14. Bourezg, Z.; Cartiser, N.; Ettouati, L.; Guillon, J.; Lacoudre, A.; Pinaud, N.; Le Borgne, M.; Fessi, H. Structural elucidation of two photolytic degradation products of tetrabenazine. J. Pharm. Biomed. Anal. 2014, 91, 138-143. [CrossRef] [PubMed]

15. Senta-Loys, Z.; Bourgeois, S.; Valour, J.-P.; Briançon, S.; Fessi, H. Orodispersible films based on amorphous solid dispersions of tetrabenazine. Int. J. Pharm. 2017, 518, 242-252. [CrossRef] [PubMed]

16. Senta-Loys, Z.; Bourgeois, S.; Pailler-Mattei, C.; Agusti, G.; Briançon, S.; Fessi, H. Formulation of orodispersible films for paediatric therapy: Investigation of feasibility and stability for tetrabenazine as drug model. J. Pharm. Pharmacol. 2017, 69, 582-592. [CrossRef] [PubMed]

17. Bala, R.; Pawar, P.; Khanna, S.; Arora, S. Orally dissolving strips: A new approach to oral drug delivery system. Int. J. Pharm. Investig. 2013, 3, 67-76. [CrossRef]

18. Dixit, R.P.; Puthli, S.P. Oral strip technology: Overview and future potential. J. Control. Release 2009, 139, 94-107. [CrossRef]

19. Nagaraju, T.; Gowthami, R.; Rajashekar, M.; Sandeep, S.; Mallesham, M.; Sathish, D.; Shravan Kumar, Y. Comprehensive review on oral disintegrating films. Curr. Drug Deliv. 2013, 10, 96-108. [CrossRef]

20. Bax, A.; Davis, D.G. Practical aspects of two-dimensional transverse NOE spectroscopy. J. Magn. Reson. 1985, 63, 207-213. [CrossRef]

21. Desvaux, H.; Berthault, P.; Birlirakis, N.; Goldman, M.; Piotto, M. Improved versions of off-resonance ROESY. J. Magn. Reson. Ser. A 1995, 113, 47-52. [CrossRef]

22. Openshaw, H.T.; Whittaker, N. 277. The synthesis of emetine and related compounds. Part V. A stereochemically favourable synthesis of emetine. J. Chem. Soc. 1963, 1461-1471. [CrossRef]

23. Oppolzer, W. Camphor derivatives as chiral auxiliaries in asymmetric synthesis. Tetrahedron 1987, 43, 1969-2004. [CrossRef]

24. Salunke, S.; Brandys, B.; Giacoia, G.; Tuleu, C. The STEP (Safety and Toxicity of Excipients for Paediatrics) database: Part 2-The pilot version. Int. J. Pharm. 2013, 457, 310-322. [CrossRef] [PubMed]

25. Meng, F.; Trivino, A.; Prasad, D.; Chauhan, H. Investigation and correlation of drug polymer miscibility and molecular interactions by various approaches for the preparation of amorphous solid dispersions. Eur. J. Pharm. Sci. 2015, 71, 12-24. [CrossRef] [PubMed]

26. Yoo, S.; Krill, S.L.; Wang, Z.; Telang, C. Miscibility/stability considerations in binary solid dispersion systems composed of functional excipients towards the design of multi-component amorphous systems. J. Pharm. Sci. 2009, 98, 4711-4723. [CrossRef] [PubMed]

27. Barra, M.; Chen, N. Kinetic studies on the thermal cis-trans isomerization of 1,3-diphenyltriazene in aqueous solution. Effects of acids and bases. J. Org. Chem. 2000, 65, 5739-5744. [CrossRef]

(C) 2019 by the authors. Licensee MDPI, Basel, Switzerland. This article is an open access article distributed under the terms and conditions of the Creative Commons Attribution (CC BY) license (http://creativecommons.org/licenses/by/4.0/). 